\title{
Impact of Host Genetic Players on Covid-19 Disease Severity: A Review of Current Knowledge and Future Prospect
}

\author{
Muhammad Sougatul Islam ${ }^{1}$, Shabnoor Binte Dayem ${ }^{1}$ and Munia Amin ${ }^{1}$ \\ ${ }^{1}$ BioTED, Darussalam, Mirpur, Dhaka 1216, Bangladesh. \\ *Correspondence: msis201@gmail.com (Dr. Muhammad Sougatul Islam MRes, Executive Director, BioTED, \\ Darussalam, Mirpur, Dhaka 1216, Bangladesh).
}

\begin{abstract}
The year 2020 has been more life-changing and eventful than ever due to the COVID-19 which has led us into this worldwide crisis. An interesting revelation has been made that the coronavirus is not entirely new to us as we are being infected by three types of seasonal coronavirus every year in winter resulting in the seasonal cold. However, SARS-CoV-2 (Severe Acute Respiratory Syndrome Corona Virus-2) has pioneered this pandemic in Wuhan, China last year, which has been named COVID-19. Since then, many nations were seen to have responded differently from one another against this virus such as European nations facing more devastation than the Middle East region in this pandemic. The reasons behind these phenomena were assumed to be the different safety measures taken by the nations but in reality, it has been known that the host genetics are responsible for the devastating effects of COVID-19. Many research findings have pointed out that ACE2, TMPRSS2, and HLA genes in the host genomes are responsible for the virus entry and subsequent immune response. Several studies conducted by different nations have found different COVID-19 variations within which three genes seem to provide clues explaining individual population's differential disease susceptibility and severity of these viral strains. This review paper has summarized the recent research findings on ACE2, TMPRSS2, and HLA gene variations in different populations, and its effect on causing severity of COVID-19 among individuals, which would be helpful to persuade the importance of such patterns in genetic variation within Bangladeshi population; so that personalized treatment may be formulated or repurposed drugs may be used to lower the profound impact of SARS-CoV-2.
\end{abstract}

Keywords: SARS-CoV-2, COVID-19, Angiotensin enzyme, TMPRSS2, HLA, Polymorphism, and Variants.

\section{INTRODUCTION:}

The novel corona virus named as SARS-CoV-2 has shaken the world by bringing the disastrous pandemic of the century. This corona virus outbreak has become the top alarming global health crisis of our time. Although many deadly virus outbreaks in the past caused more life-threatening and devastating effects on the human race, COVID-19 has scared us the most by changing the lifestyle of the global population. This

UniversePG I www.universepg.com crown shaped virus was transmitted from animals (bats, civets, cats) into the human race and began spreading (Hou et al., 2020).

Due to the pandemic and panic situations, everyone might think that this corona virus is new to us but in reality, all of us have already been infected by this virus at least once a year. Already four types (HCoVNL63, HCoV-229E, HCoV-OC43, and HCoV-HKU1) of seasonal corona viruses have claimed to be moving 
around and expressing common seasonal colds in children and adults. There are three more types (SARS-CoV-1: the severe acute respiratory syndrome corona virus, MERS-CoV: the Middle East respiratory syndrome [MERS] corona virus and SARS-CoV-2) of corona viruses which cause life jeopardizing respiratory diseases like the Middle East respiratory syndrome (MERS) and severe acute respiratory syndrome (SARS) (Ovsyannikova et al., 2020).

The SARS-CoV-2 corona virus started this pandemic in Wuhan, China in 2019 by causing mild respiratory infection to acute respiratory infection and death. Till June 2021, 178,503,429 confirmed cases of COVID-19 and 3,872,457 deaths were reported to the World Health Organization from Bangladesh alone (World Health Organization Dashboard).

\section{Background}

As we know, patients with pre-existing health conditions (cancer, cardiovascular disease, diabetes, respiratory diseases etc.) and older age are more vulnerable towards this virus because of the higher death rates among older and/or immune-suppressed individuals (Feng et al., 2020). But this pattern was seen to be broken from time to time where some young and healthy individuals were suffering from the severe consequences from the viral infection and some older individuals seemed to be recovering faster than anyone from the virus (Dong et al., 2019). Now, the reason behind this differential disease severity among individuals with the factors deciding whom to affect more and whom to affect less with this virus needs to be uncovered. Hence, the host genomics has to be brought into light this time instead of virus genomics as the explanations lie within our genome. Human genomics can be referred to as a person's entire DNA (genes) content present within one cell and those gene's in between interactions. Some variations like DNA polymorphisms: Single Nucleotide Polymorphisms (SNP) is present within these genes which eventually decide how individuals will react to different infectious diseases (Hartl et al., 2014). Single nucleotide polymorphisms are variations within the building blocks (nucleotide bases) of the genes. For example, in a population, most individuals have base $\mathrm{G}$ (Guanine) in a certain position of the genome but in some minor number of individuals from that populaUniversePG I www.universepg.com tion has base A (Adenine) on that position, therefore it can be said that a single nucleotide polymorphism has taken place in those minor group of the population by replacing the nucleotide base. These types of replacements may lead to alterations in amino acid sequences thus changing the entire protein. This phenomenon ultimately regulates an individual's reaction towards different infections, diseases, and treatments (Zhang et al., 2004).

Several researches were done to find a link between these variations in COVID-19 disease severity and host genetic factors; finally, which led them to zero in on three specific genes. ACE2 (Angiotensin-Converting Enzyme 2), TMPRSS2 (Transmembrane Serine Protease 2) \& HLA (Human Leukocyte Anti-gen) in our body acts as the entry point for the SARS-CoV-2 virus. ACE2 gene codes for the angiotensin-converting enzyme 2 or the ACE2 receptor (Hou et al., 2020). These ACE2 receptors are found on the cell membranes of lungs, arteries, heart, kidney, and intestines. The ACE2 enzyme converts angiotensin-I hormone to angiotensin-II hormone (causes vaso-constriction) to higher the blood pressure in response to the limited blood flow of the kidney (Heurich et al., 2014). Then to balance this situation ACE2 enzyme lowers the blood pressure by converting the angiotensin-II hormone to angiotensin-(1-7) hormone (induces blood vessel dilation).The spike (S) membrane protein of the SARS-CoV-2 virus latches itself onto the ACE2 receptors on the human cells much like putting a key into the lock. After inserting itself into the cytoplasm of the cell the virus uses the host cell machinery to reproduce itself. By acknowledging the role of ACE2 genes in SARS-CoV-2 virus entry into our body, it is clear that any SNP within this gene would alter the mechanism of the viral entry (Heurich et al., 2014). The notable key information is that the ACE2 gene always works as a team with the TMP-RSS2 gene to influence the SARS-COVID-2 entry into the host body. TMPRSS 2 gene encodes Trans-membrane Protease Serine 2 enzyme and it is located in close proximity to ACE2 (Benetti et al., 2020). TMPRSS2 is known to be a crucial gene in prostate cancer as it has an impactful; influence over the growth of prostate cancer. The TMPRSS2 cleaves the spike (S) protein of the coronavirus into $\mathrm{S} 1$ and $\mathrm{S} 2$ subunits before their 
binding with the ACE2 receptor. The S1 subunit mainly binds with the host cell ACE2 receptors and the S2 subunit mediates membrane fusion (Benetti et al., 2020). Another important function of TMPRSS2 is the cleavage of the ACE2 receptor. After binding of $\mathrm{S}$ protein to ACE2 receptors, it requires certain modifications to facilitate the viral uptake (Hou et al., 2020). A third prime genetic player is the HLA gene which encodes MHC (Major Histocompatibility Complex) Class-I protein. MHC Class-I protein is responsible for displaying peptide fragments (antigen) of viral protein to our immune system to activate their function to fight the pathogenic virus (Ovsyannikova et al., 2020). Therefore, an association between HLA gene variants and the Covid-19 disease severity is speculated. Many research findings have indicated that the existence of some variants in the HLA gene lowers the binding capacity of MHC-Class-I protein to the antigen of SARS-COVID-2 virus, thus making individuals with this HLA variant type more vulnerable towards the coronavirus severity as they cannot signal their immune response against it. In contrast, some types of variants in this gene facilitate more efficient binding capacity to MHC-Class-I protein with the antigen. Therefore people with those particular types of variant can gain enhanced immunity which may result in lower severity of COVID-19 (Nahid, 2021; Hasan et al., 2021; Ovsyannikova et al., 2020).

In this review, a proper understanding and a sum up of the study findings on how host genomics perform a major part in an individual's disease severity towards COVID-19. This review will be pointing out the crucial variants present on ACE2, TMPRSS2 \& HLA genes and how any presence or absence of these variants may alter one's response towards COVID-19. All these conjectures will solely follow the recently published literature, as many nations' research has published several findings regarding the association between human genomics and COVID-19 disease severity.

Important Genetic Variants in ACE2 - ACE2 gene encoding Angiotensin-Converting Enzyme-2 receptor provides an entry point inside our body for SARSCOVID-2 virus. The existence of SNP within this gene affects the corona viruses' binding affinity with the ACE2 receptor, therefore making the entrance of UniversePG I www.universepg.com
SARS-CoV-2 inside a human cell more difficult or easy. The ACE2 gene is 41,116 bp long, contains 21 exons, and encodes 788 amino acids long protein (Lippi et al., 2020). The prominent ratio of males getting more affected by the severity of COVID-19 is more observed because ACE2 receptors are encoded on the Xp22.2 chromosome and as males got only one copy of it so any absence or presence of a certain variant will have greater impact as males does not have another spare $\mathrm{X}$ chromosome like women which can maintain the normal function. Therefore, males are more struck by the severity of the virus than the females (Benetti et al., 2020). An ACE2 peptidase domain (PD) is present on the ACE2 binding site for the $\mathrm{S}$ protein of SARS-COVID-2 with a following neck domain that helps in the functioning of the dimerization process and protein stability (Gemmati et al., 2020). Donato et al. have theoretically suggested that the protein stability and it dimerization were greatly influenced by certain variations within the amino acid components of those, and therefore they can interrupt the SARS-CoV-2 binding with the receptor (Gemmati et al., 2020).

Li et al. (2005) have suggested five major residues (Lys31, Glu35, Asp38, Met82 and Lys353) in the ACE2 receptor which may alter the binding efficiency of the receptor with the $\mathrm{S}$ protein of coronavirus. Three other variants rs758278-442 (Lys31Lys), rs1348114695 (Glu35Lys), and rs766996587 (Met82Ile) were found by Lee et al. (2020) in Asian, European (EUR) \& East Asian, African populations respectively but these variants were estimated to have very few impacts on the ACE2 receptor. In another vast study of ACE2 polymorphism in over 400 populations (Stawiski et al., 2020) have demonstrated nine variants (Ser19Pro, Ile21Val, Glu23Lys, Lys26Arg, Thr27Ala, Asn64Lys, Thr92Ile, Gln102Pro, His378Arg) and another 17 variants (Lys31Arg, Asn33Ile, His34Arg, Glu35Lys, Glu37Lys, Asp38Val, Tyr50Phe, Asn51Ser, Met62Val, Lys68Glu, Phe72Val, Tyr83His, Gly326Lys, Gly352 Val, Asp355Asn, Gln388Leu, and Asn509Tyr). In here, the former set of variants were claimed to provide a more efficient binding attraction and the latter group is of lesser binding affinity towards SARSCoV-2 spike protein (Stawiski et al., 2020). Another three pivotal variants (p.Lys26Arg, p.Gly211Arg, and 
p.Asn720Asp) found by (Benetti et al., 2020) recognized to be interrupting the ACE2 cleavage process and thereby affecting viral intake, present in the Italian Population and absent in the East Asian (EAS) population. A study on EUR and EAS populations done by Li et al. (2020) showed one variant Ile468Val which was considered to have a lower binding affinity for the spike protein of SARS CoV-2 (Al-Mulla et al., 2020) showed that p.Asn720Asp and p.Lys26Arg variants (previously found by (Benetti et al., 2020) and (Stawiski et al., 2020) respectively can maximize the reaction between ACE2 and SARS-CoV-2 and they were found in EUR and Iranian Populations (absent in Kuwaiti population).

Table 1: ACE2 variants with their plausible effect on various populations in the world are summarized.

\begin{tabular}{|c|c|c|c|c|}
\hline Serial & Variants & Effect of the variants & Population & Reference \\
\hline \multirow{3}{*}{1.} & Lys26Arg & \multirow{3}{*}{$\begin{array}{l}\text { Affects TMPRSS2 dependent cleavage of } \\
\text { ACE2 }\end{array}$} & \multirow{3}{*}{ Italian } & \multirow{3}{*}{ (Benetti et al., 2020) } \\
\hline & Gly211Arg & & & \\
\hline & Asn720Asp & & & \\
\hline \multirow{17}{*}{2.} & Lys31Arg & \multirow[t]{17}{*}{ Lower binding affinity for SARS CoV-2 } & \multirow{17}{*}{$\begin{array}{c}\text { Over } 400 \\
\text { populations }\end{array}$} & \multirow{17}{*}{ (Stawiski et al., 2020) } \\
\hline & Asn33Ile & & & \\
\hline & His34Arg & & & \\
\hline & Glu35Lys & & & \\
\hline & Glu37Lys & & & \\
\hline & Asp38Val & & & \\
\hline & Tyr50Phe & & & \\
\hline & Asn51Ser & & & \\
\hline & Met62Val & & & \\
\hline & Lys68Glu & & & \\
\hline & Phe72Val & & & \\
\hline & Tyr83His & & & \\
\hline & Gly326Lys & & & \\
\hline & Gly352Va & & & \\
\hline & Asp355Asn & & & \\
\hline & Gln388Leu & & & \\
\hline & Asn509Tyr & & & \\
\hline \multirow{9}{*}{3.} & Ser19Pro & \multirow[t]{9}{*}{ Higher binding affinity for SARS CoV-2 } & \multirow{9}{*}{$\begin{array}{c}\text { Over } 400 \\
\text { populations }\end{array}$} & \multirow[t]{9}{*}{ (Stawiski et al., 2020) } \\
\hline & Ile21Val & & & \\
\hline & Glu23Lys & & & \\
\hline & Lys26Arg & & & \\
\hline & Thr27Ala & & & \\
\hline & Asn64Lys & & & \\
\hline & Thr92Ile & & & \\
\hline & Gln102Pro & & & \\
\hline & His378Arg & & & \\
\hline 4. & Ile468Val & Lower binding affinity for SARS CoV-2 & EUR \& EAS & (Li et al., 2020) \\
\hline \multirow[t]{2}{*}{5.} & Lys26Arg & \multirow[t]{2}{*}{ Increase binding affinity for SARS CoV-2 } & \multirow[t]{2}{*}{ EUR \& Iranian } & $\begin{array}{l}\text { (Stawiski et al., 2020; } \\
\text { Al-Mulla } \text { et al., 2020) }\end{array}$ \\
\hline & Asn720Asp & & & $\begin{array}{l}\text { (Benetti et al., 2020; } \\
\text { Al-Mulla } \text { et al., 2020) }\end{array}$ \\
\hline \multirow[t]{2}{*}{6.} & Arg708Gln & \multirow[t]{2}{*}{ Inhibit viral entry } & $\begin{array}{l}\text { Kuwaiti \& } \\
\text { Iranian }\end{array}$ & (Al-Mulla et al., 2020) \\
\hline & Arg708Trp & & $\begin{array}{c}\text { Kuwaiti, Iranian, } \\
\text { EUR, LAM \& } \\
\text { EAS }\end{array}$ & $\begin{array}{l}\text { (Hou et al., 2020; Al- } \\
\text { Mulla et al., 2020) }\end{array}$ \\
\hline
\end{tabular}


The authors further found two variants p.Arg708Gln and p.Arg708Trp in Iranian and Kuwaiti-Iranian populations respectively (Al-Mulla et al., 2020). Their research explained that these variants are located in the ACE2 cleavage site (important for the entrance of the virus) and the inhibition of the viral entry is dependent on them. From their findings, the authors speculated that as Kuwaiti population seemed to be protected against the horrifying effects this outbreak has created, as they lack the damaging variant p.Asn720Asp and have the protective variant p.Arg-708Gln and p.Arg708Trp in their genome (Al-Mulla et al., 2020). ACE2 variants with their plausible effect on various populations in the world are summarized in Table 1.

\section{Important Genetic Variants in TMPRSS2}

It has already been established through several research findings that the TMPRSS2 gene is crucial for SARS-CoV-2 viral spike protein cleavage and its subsequent binding and entrance inside the human cells. So, certain human genetic variants situated in this gene may also affect the interactivity between TMPRSSS2 and the virus. TMPRSS2 gene is $44 \mathrm{~Kb}$ long, contains 14 axons', and encodes for 452 amino acid long protein (Antalis et al., 2011). TMPRSS2 is located on 21q22.3; hence speculations have been made that the patients who already have down syndrome would be at an imperiled position for COVID19 infection (Antalis et al., 2011). Afar et al. suggested that Val292 \& Met478 residues are associated with the photolytic function of TMPRSS2. In (Lee et al., 2020) attempted to find variations within these residues across different populations but failed to find any association. In a major analysis study done by (Paniri et al., 2020) in African (AF), American (AMR), EUR, EAS and South Asian (SAS) populations, three major variants (Gly8Asp, Gly8Val \& Val197Met) were found which resides in the random coil and the extend- ed beta strand regions on TMPRSS2 protein respectively. The authors have predicted both Gly8Asp, Gly8Val variants can interrupt TMPRSS2 function on providing a gateway for SARS-CoV-2 inside our cells by forming a new proteolysis' cleavage site at their position in TMPRSS2 (Paniri et al., 2020). Converse-ly, Val197Met also alters the function of TMPRSS2 in helping viral entry by constructing a large protein pocket at this position affecting the secondary structure of TMPRSS2. Further, another six variants (rs456142, rs462574, rs456298, rs12627374, rs12473206, and rs75036690) were demonstrated through this research, which can modify the splicing sites in the mRNA thereby influencing the expression of TMPRSS2 gene and subsequent SARS-CoV-2 entry (Paniri et al., 2020). Hou et al. (2020) showed 6 germ line deleterious variants (p.Val160Met, p.Gly181Arg, p.Arg240Cys, p.Gly259Ser, p.Pro335Leu, and p.Gly432Ala) in the coding regions of TMPRSS2 gene within EAS, SAS, and Finnish (FIN) populations. Also another variant p.Asp435Tyr was found by the authors with a small allele frequency in the EUR population and the catalytic substrate binding of TMPRSS2 could be interrupted by that (Hou et al., 2020). Both (Asselta et al., 2020 and Benetti et al., 2020) have suggested two sets of haplotypes (sets of SNP) in the TMPRSS2 gene which might be responsible for enhancing the regulation of the TMPRSS2 gene expression. First set rs463727, rs34624090, rs55964536, rs734056, rs4290734, rs34783969, rs11702475, rs35899679, and rs35041537 found in Europeans and absent in Asians and the second set contains rs2070788, rs9974589, rs7364083 found in higher allele frequency in Italian population than EAS population (Asselta et al., 2020). TMPRSS2 variants distributions with their effect on various populations are summarized in Table 2.

Table 2: TMPRSS2 variants distributions with their effect on various populations are summarized.

\begin{tabular}{|c|l|c|c|c|}
\hline Serial & Variants & Effect & Population & Reference \\
\hline \multirow{3}{*}{1.} & Val160Met & \multicolumn{2}{|c|}{ Germline deleterious variants } & FAS, SAS, and \\
FIN & (Hou et al., 2020) \\
\cline { 2 - 3 } & Gly181Arg & & \\
\cline { 2 - 3 } & Arg240Cys & & \\
\cline { 2 - 4 } & Gly259Ser & & \\
\cline { 2 - 5 } & Pro335Leu & & \\
\cline { 2 - 5 } & Gly432Ala & & EUR & (Hou et al., 2020) \\
\hline 2. & Asp435Tyr & Affects catalytic substrate binding of TMPRSS2 & & \\
\hline
\end{tabular}




\begin{tabular}{|c|c|c|c|c|}
\hline \multirow[t]{6}{*}{3.} & rs456142 & \multirow[t]{6}{*}{ Influence the expression of TMPRSS2 gene } & \multirow{6}{*}{$\begin{array}{c}\text { AF, AMR, } \\
\text { EUR, EAS, } \\
\text { SAS }\end{array}$} & \multirow[t]{6}{*}{ (Paniri et al., 2020) } \\
\hline & rs462574 & & & \\
\hline & rs456298 & & & \\
\hline & rs12473206 & & & \\
\hline & rs75036690 & & & \\
\hline & rs12627374 & & & \\
\hline \multirow[t]{3}{*}{4.} & Gly8Asp & \multirow[t]{3}{*}{ Affects viral entry } & \multirow{3}{*}{$\begin{array}{c}\text { AF, AMR, } \\
\text { EUR, EAS, } \\
\text { SAS }\end{array}$} & \multirow[t]{3}{*}{ (Paniri et al., 2020) } \\
\hline & Gly8Val & & & \\
\hline & Val197Met & & & \\
\hline \multirow{9}{*}{5.} & rs463727 & \multirow[t]{9}{*}{ Up regulates TMPRSS2 gene expression } & \multirow{9}{*}{ EUR } & \multirow{9}{*}{$\begin{array}{c}\text { (Benetta } \text { et al., 2020; } \\
\text { Asseta } \text { et al., 2020) }\end{array}$} \\
\hline & rs34624090 & & & \\
\hline & rs55964536 & & & \\
\hline & rs734056 & & & \\
\hline & rs4290734 & & & \\
\hline & rs34783969 & & & \\
\hline & rs11702475 & & & \\
\hline & rs 35899679 & & & \\
\hline & rs 35041537 & & & \\
\hline \multirow{3}{*}{6.} & rs2070788 & \multirow[t]{3}{*}{ Upregulates TMPRSS2 gene expression } & \multirow[t]{3}{*}{ EAS \& Italian } & \multirow{3}{*}{$\begin{array}{l}\text { (Benetta } \text { et al., 2020; } \\
\text { Asseta } \text { et al., 2020) }\end{array}$} \\
\hline & rs9974589 & & & \\
\hline & rs7364083 & & & \\
\hline
\end{tabular}

Important Genetic Variants in HLA - HLA (Human Leukocyte Antigen) gene is already a more familiar name in genomics than ACE2 \& TMPSS2 for the function its encoded protein's (MHC Class-I) have in the immune system. As MHC Class-I proteins are able to present viral antigen to our immune system; therefore they are related with individual's susceptibility towards SARS-CoV-2 (Ovsyannikova et al., 2020). It was previously observed in many research findings that various types of HLA variants can make MHC Class-I protein more or less capable of creating a linkage with viral antigens which thereby decide how strongly our cellular defense will fight the pathogen. Certain HLA variants in infectious diseases like tuberculosis, leprosy, HIV, hepatitis B, and influenza have given infected individuals more or less immunity to recover the infection (Shi et al., 2020). It is surpriseing that despite having such an important association of this gene with the recent pandemic, very little research showing different HLA variants related to SARS-CoV-2 was published.

Nguyen et al. (2020) pointed out two variants HLA$\mathrm{B}^{*}$ 15:03 \& HLA-B*46:01, where the former variant increases the protein's ability of adhering itself with the SARS-CoV-2 antigen thereby gaining more immunity and the latter one lowers the binding ability with viral antigen giving less protection.

Necessity to Acknowledge Host Genomics' Role to Fight this Pandemic - In this race against the deadly virus, every nation is leaving no rock unturned to win. "Till now no effective antiviral treatment against COVID-19 has been available". In some countries like India Covid-19 kept spreading faster than many developed countries and it weakened people both emotionally and economically. Many nation's (Europe, USA, Asia, Middle East) research findings have shed some light on the relationship between differential disease severity of COVID-19 and host genetic factors like ACE2 \& TMPRSS2 genes in their population (Afar et al., 2001; Shi et al., 2020). They have pointed out various genetic variations in ACE, TMPRSS2 \& HLA genes which explain the cases of younger and healthy people suffering more from the virus than older and immune suppressed individuals. Certain previously designed drugs which worked effectively against diseases related to biological path-ways affected by ACE2 and TMPRSS2 genes were suggested to be useful to reduce COVID-19 disease severity. Both (Hou et al., 2020; Bosso et al., 2020) suggested that drugs like melatonin, hydroxyl-chloro- 
quine, and chloroquine can be reused to hinder viral arrival into the host cell by barricading its ACE2 entrance. In addition to that, the authors also proposed that camostat mesylate (TMPRSS2 inhibitor) an approved drug in Japan can also be reused to treat COVID-19 as it can hamper the endosomal dependent entry of SARS-CoV-2 into the host cell (Afar et al., 2001; Zhang et al., 2004). These studies also pointed out the fact that the absence or presence of variations within these two genes might alter the clinical efficacy of these drugs in individuals. As we are going through the second wave of the COVID-19 pandemic, Bangladesh should also step forward to find our population's genetic allies with differential COVID-19 severity. By acquiring some objectives like a) finding out the hidden variation patterns in these genes which can explain that why so many deaths are occurring in infected young individuals; b) if those suggested repurposed drugs help reduce the severity of COVID-19 in our population; c) any presence or absence of variation in our genome has given us more advantage or disadvantage in this pandemic; d) finding these variations might be a pioneer to design a personalized treatment for us to fight COVID-19. By our proposed objectives our nation can also be prepared to face any similar infections like Covid-19.

\section{CONCLUSION:}

There are some research findings about the relationship between host genomics and COVID-19 disease severity are available and many nations in the world are trying to find similar answers and solutions against the enemy whom we all have been fighting for more than a year. Therefore it seems necessary to have a global study in order to identify population based genomic signatures and their associations with the SARS-CoV-2. We can try to put our people in a better position in this pandemic by pursuing research questions like, a) what kinds of SNPs are present in our population's ACE2, TMPRSS2 \& HLA genes? b) Are they associated with COVID-19 disease severity in our population? c) Does any specific variation put any certain group in the population at more risk towards COVID-19 or gives us more advantage against it? d) Do we have any common pattern of variation with any other population? e) Can certain repurposed drugs used in other diseases targeting the same biological

UniversePG I www.universepg.com pathway as COVID-19, be reused to reduce the severity of corona? f) Can the knowledge of these variations help us to design a personalized treatment against COVID-19 and prepare us for any similar infectious disease in the future? This review concludes by stating that finding answers to these research questions may give us a new hope and perspective to make our way out from this pandemic.

\section{ACKNOWLEDGEMENT:}

The research project was financially supported with proper guidance and help for data analysis in the Department of Biotechnology and Genetic Engineering, Islamic University, Bangladesh. Many thanks, to the co-workers supporting for successful completion of the research work.

\section{CONFLICTS OF INTEREST:}

The authors declared no conflicts of the interest in terms of authorship and publication of this article.

\section{REFERRENCES:}

1) Afar et al. (2001). Catalytic cleavage of the androgen-regulated TMPRSS2 protease results in its secretion by prostate and prostate cancer epithelia. Can. research, 61(4), pp.1686-1692. https://pubmed.ncbi.nlm.nih.gov/11245484/

2) Al-Mulla et al. (2020). A comprehensive germ-line variant and expression analyses of ACE2, TMPRSS2 and SARS-CoV-2 activator FURIN genes from the Middle East: Combating SARS-CoV-2 with precision medicine. BioRxiv https://doi.org/10.1101/2020.05.16.099176

3) Antalis et al. (2011). Membrane-anchored serine proteases in health and disease. Progress in molecular biology and translational science, 99, pp.1-50.

https://doi.org/10.1016/B978-0-12-385504-6.0 $\underline{0001-4}$

4) Asselta et al. (2020). ACE2 and TMPRSS2 variants and expression as candidates to sex and country differences in COVID-19 severity in Italy. Aging (Albany NY), 12(11), p.10087. https://doi.org/10.18632/aging.103415

5) Benetti, E., (2020). GEN-COVID Multicenter Study. ACE2 genes variants may underlie inter individual variability and susceptibility to 
COVID-19 in the Italian population. Eur. J. Hum. Genet, 28, pp.1602-1614. https://doi.org/\%2010.1038/s41431-020-0691-z

6) Bosso et al. (2020). The two faces of ACE2: the role of ACE2 receptor and its polymerphisms in hypertension and COVID-19. Molecular Therapy-Methods \& Clinical Development, 18, pp.321-327.

7) Dong et al. (2020). Epidemiological characteristics of 2143 pediatric patients with 2019 coronavirus disease in China. Pediatrics https://doi.org/10.1542/peds.2020-0702

8) Gemmati et al. (2020). COVID-19 and individual genetic susceptibility/receptivity: role of ACE1/ACE2 genes, immunity, inflamemation and coagulation. Might the double $\mathrm{X}$ chromo-some in females be protective against SARS-CoV-2 compared to the single X-chromosome in males? International journal of molecular sciences, 21(10), p.3474.

https://doi.org/10.3390/ijms21103474

9) Hasan M, Ferdous MM, Islam A, Hossain MR, Rahman MS, Ahmed T, and Islam MR. (2021). Scenario of Bangladesh in various sectors due to Covid-19 pandemic. Am. J. Pure Appl. Sci., 3(4), 79-84. https://doi.org/10.34104/ajpab.021.079084

10) Hartl, D.L. (2014). Essential genetics: A genomics perspective. Jones \& Bartlett Publishers.

11) Heurich et al. (2014). TMPRSS2 and ADAM17 cleave ACE2 differentially and only proteolysis by TMPRSS2 augments entry driven by the severe acute respiratory syndrome coronavirus spike protein. J. of virology, $\mathbf{8 8}(2)$, pp.1293-1307.

https://www.amazon.com/Essential-GeneticsPerspective-Daniel-Hartl/dp/1449686885

12) Heurich et al. (2014). TMPRSS2 and ADAM17 cleave ACE2 differentially and only proteolysis by TMPRSS2 augments entry dri-ven by the severe acute respiratory syndrome coronavirus spike protein. Journal of virology, 88(2), pp.1293-1307. https://doi.org/10.1128/JVI.02202-13

13) Hou et al. (2020). New insights into genetic susceptibility of COVID-19: an ACE2 and
TMPRSS2 polymorphism analysis. BMC medicine, 18(1), pp.1-8.

https://doi.org/10.1186/s12916-020-01673-z

14) Lee et al. (2020). A survey of genetic variants in SARS-CoV-2 interacting domains of ACE2, TMPRSS2 and TLR3/7/8 across populations. Infection, Genetics and Evolution, 85, p.104507.

https://doi.org/10.1016/j.meegid.2020.104507

15) Li et al. (2005). Structure of SARS coronavirus spike receptor-binding domain complexed with receptor. Science, 309(5742), pp. 1864-1868.

https://doi.org/10.1126/science. 1116480

16) Li et al. (2020). Genetic variability of human angiotensin-converting enzyme 2 (hACE2) among various ethnic populations. Molecular genetics \& genomic medicine, 8(8), p.e1344. https://doi.org/10.1002/mgg3.1344

17) Lippi et al. (2020). Do genetic polymorphisms in angiotensin converting enzyme 2 (ACE2) genes play a role in coronavirus disease 2019 (COVID-19)? Clinical Chemistry and Laboratory Medicine (CCLM), 58(9), pp.14151422. https://doi.org/10.1515/cclm-2020-0727

18) Nahid AHM. (2021). Resistance, unrest, protest and demonstration provoked by COVID19: a case study of Bangladesh, Asian J. Soc. Sci. Leg. Stud., 3(2), 23-34. https://doi.org/10.34104/ajssls.021.023034

19) Nguyen et al. (2020). Human leukocyte antigen susceptibility map for SARS-CoV-2 ahead of print April 17. J Virol, pp.00510-20. https://doi.org/10.1002/mgg3.1344

20) Ovsyannikova et al. (2020). The role of host genetics in the immune response to SARSCoV-2 and COVID-19 susceptibility and severity. Immunological reviews, 296(1), pp. 205-219.

https://doi.org/10.1515/cclm-2020-0727

21) Paniri et al. (2020). First comprehensive computational analysis of functional consequences of TMPRSS2 SNPs in susceptibility to SARS-CoV-2 among different populations. Journal of Bimolecular Structure and Dynamics, pp.1-18. https://doi.org/10.1080/07391102.2020.1767690 
22) Shi et al. (2020). COVID-19 infection: the perspectives on immune responses, Cell Death \& Differentiation, 27, pp.1451-1454.

https://www.nature.com/articles/s41418-0200530-3

23) Stawiski et al. (2020). Human ACE2 receptor polymorphisms predict SARS-CoV-2 susceptibility. BioRxiv. https://doi.org/10.1101/2020.04.07.024752

24) Surveillances, V., (2020). The epidemiological characteristics of an outbreak of 2019 novel coronavirus diseases (COVID-19) - China, 2020. China CDC weekly, 2(8), pp.113-122. https://doi.org/10.46234/ccdcw2020.032

25) Zhang et al. (2004). Haplotype block partitioning and tag SNP selection using genotype data and their applications to association studies. Genome research, 14(5), pp.908-916. https://doi.org/10.1101/gr.1837404

Citation: Islam MS, Dayem SB, and Amin M. (2021). Impact of host genetic players on Covid-19 disease severity: a review of current knowledge and future prospect, Bangladesh. Eur. J. Med. Health Sci., 3(4), 7987. https://doi.org/10.34104/ejmhs.021.079087 @ @ 